\title{
STRUCTURAL ASSESSMENT OF THE SEISMIC BEHAVIOR OF THE DOME OF THE TAJ MAHAL
}

\section{SATWANT RIHAL ${ }^{1}$, WILLIAM KOH ${ }^{2}$, ANJALI MEHROTRA ${ }^{3}$ AND JOHN EDMISTEN ${ }^{1}$}

\author{
${ }^{1}$ Architectural Engineering Department - College of Architecture \& Environmental Design \\ Cal Poly State University, San Luis Obispo, USA \\ e-mail: srihal@calpoly.edu (*corresponding author) \\ ${ }^{2}$ Consulting Structural Engineer, Los Angeles, California, USA \\ e-mail: william@williamkohassociates.com \\ ${ }^{3}$ ISISE, Department of Civil Engineering \\ University of Minho, Guimaraes, Portugal \\ e-mail: anjali.a.mehrotra@gmail.com
}

Keywords: Historical Domes, Taj Mahal, Structural Analysis, Seismic Behavior, Earthquake Resistance

\begin{abstract}
This paper presents the results of a study of the structural assessment of the seismic behavior of the main dome of the Taj Mahal, in Agra, India. Built by the Moghul emperor Shah Jahan between 1632 - 1648 AD, the structure is one of most famous buildings in the world and the finest and most sophisticated symbol of Moghul architecture in India. As it is located in a zone of moderate seismicity, there is an urgent need for ensuring the structural safety and preservation of this iconic cultural heritage for future generations. The objective of this study is to develop a simplified approach to enhance our conceptual understanding of the mechanism of load path/transfer in the dome of the Taj Mahal under both gravity and seismic loads, as well as to better understand the influence of the geometry of the dome on its structural behavior. Using the software SAP2000, a finite element model of the dome is created and analyzed under the action of gravity and seismic loads, with the seismic loading assumed to have a PGA of $0.25 \mathrm{~g}$ based on the results of a study conducted by the Indian National Disaster Management Authority. The results obtained include plots of the distribution of nodal reactions at selected levels to represent the lateral load behavior of the dome of the Taj, as well as plots illustrating the paths of load transfer under the action of gravity and seismic loads. Free body diagrams of selected rings are also presented to illustrate the 'hoop' forces in the dome, while simplified internal stresses are computed and compared with known material properties. Observations are also presented about the effect of the dome geometry, especially the bulging part of the dome, on the distribution of reactions and the resulting mechanism of load transfer in the structure under both gravity and seismic loading.
\end{abstract}




\section{INTRODUCTION}

World cultural heritage has found rich and creative expression in beautiful and expansive works of domed architecture such as the Pantheon in Rome, built by Emperor Hadrian between 120-124 AD, the Hagia Sophia in Istanbul, Turkey built in $6^{\text {th }}$ century AD and the Taj Mahal in Agra, India built by the Emperor Shah Jahan between 1632-1648 AD. The survival of these structures to this day inspires the fundamental curiosity - how did the ancient builders build such structures with the materials (e.g. stone or brick, and mortar) and knowledge available to them at that time? A lot can be learned from their wisdom, specifically through their understanding of materials, geometry of structural forms, structural stability, and the techniques of construction.

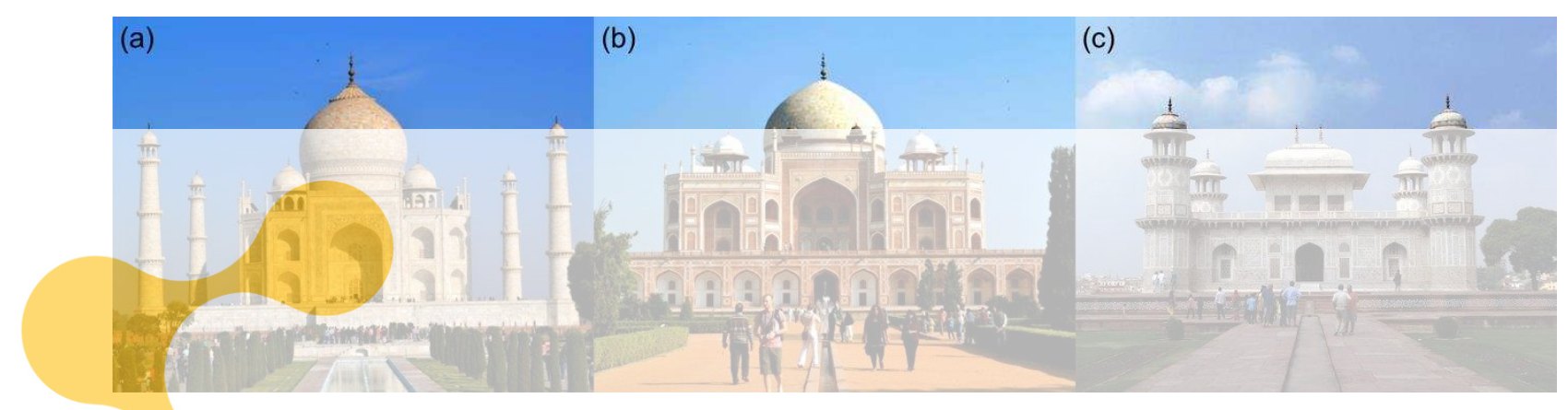

Figure 1: (a) The Taj Mahal in Agra, (b) Humayun's tomb in Delhi and (c) Itmad-Ud-Daulah's tomb in Delhi
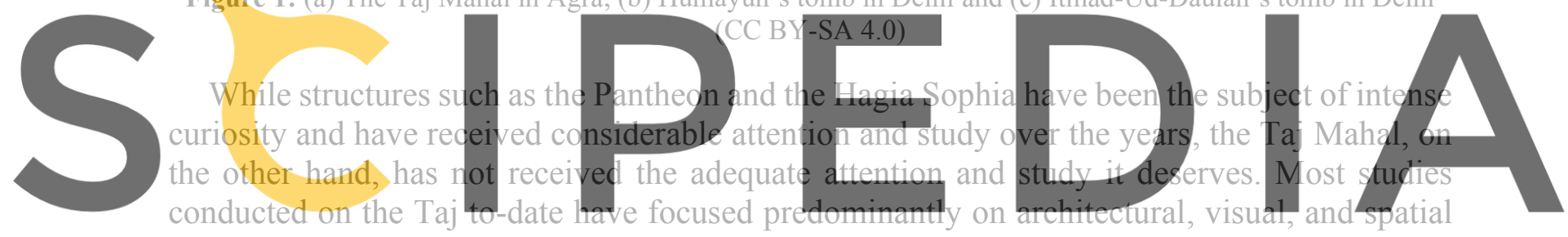

aspects of the structure as well as on the Moghul gardens that surround it [1-4], while limited

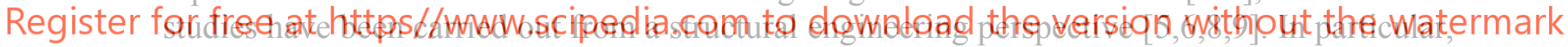

the large, unique onion-shaped dome of the structure invites curiosity and merits further investigation.

This study aims to investigate the behavior of the main dome of the Taj Mahal under gravity and seismic loads in order to enhance our conceptual understanding of the load paths and mechanism of load transfer in the structure; and to better understand the influence of the geometry of the dome on its structural behavior under gravity as well as seismic loads.

In order to do this, the background and construction history of the Taj Mahal are first studied and available drawings, material information and results of previous structural investigations are examined.

Based on these studies, the dome geometry is established, which is subsequently used to generate a finite element (FE) model in SAP2000 [7]. In the first instance, a relatively simple FE model is generated by dividing the dome into a series of circular rings, which are then divided into sixteen radial segments (lunes). This FE model is then analyzed under the action of gravity and seismic loads, with the seismic loading corresponding to the maximum expected PGA on site. The results of this model provide insight into the distribution of forces/reactions in the dome under the action of gravity and seismic loads. 
A second more refined FE model of the Taj Mahal dome was then developed in order to investigate the distribution of meridional and hoop stresses in the dome (both over the height and across the dome thickness), under the same loading conditions. The resulting stresses are compared to those reported by previous structural investigations of the Taj Mahal dome $[5,6]$ as well to the material properties of the structure.

\section{BACKGROUND}

\subsection{Design and construction history}

The Taj Mahal, considered as one of the most accomplished examples of Moghul architecture in India, was built between 1632 - 1648 AD by the Moghul emperor Shah Jahan in memory of his wife Mumtaz Mahal, who died while giving birth to their fourteenth child.

While designing the structure, Shah Jahan drew inspiration from both traditional Persian architecture as well as classic Mughal architecture as exemplified by structures such as Humayun's tomb and Itmad-Ud-Daulah's tomb (Figures $1 \mathrm{~b}$ and c). In fact, according to [1], 'Taj Mahal was the logical conclusion and synthesis of several strands that already existed in Moghul architecture'. Various designs were submitted to Shah Jahan and modified according to his own suggestions, and while the identity of the architect of the final structure is heavily debated, it is widely accepted that the principal designer was Ustad Ahmad Lahauri of Lahore. Lahauri, who was a Persian, and said to be heavily involved in the construction of the structure, which was such a colossal venture that it required a whole team of architects, as w
stonecutters, inlayers, carvers, painters calligraphers, dome builders and requisitioned from the years for construction 2.2 Plan and configuration
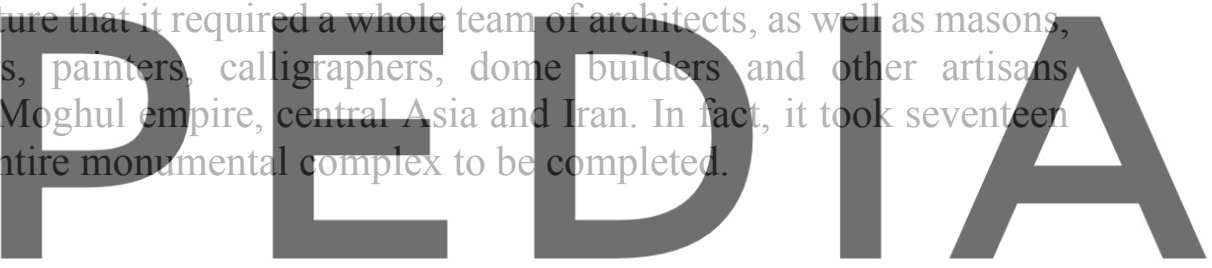

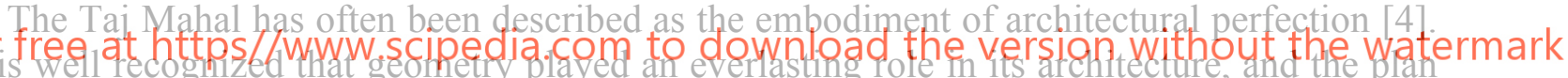
layout and configuration of the Taj Mahal has been studied and analyzed extensively by many scholars over the years [1-5].

The tomb, which is the central focus of the entire Taj Mahal complex, is a large white marble-clad structure which stands on a square plinth and consists of a symmetrical building with an iwan (an arch shaped doorway) topped by a large dome and a finial. The base structure is a large multi-chambered cube with chamfered corners forming an unequal octagon that is approximately $54.9 \mathrm{~m}$ on each of the four sides. This irregular octagonal plan is a variation of hasht bihisht ('eight paradises') plan, which typically comprises a central chamber surrounded by four chambers at the diagonals and four open fore-halls on the perpendicular axes as illustrated by Figure $2 \mathrm{a}$.

The base structure is surmounted by an inner dome and a cylindrical drum, which in turn is topped by the monumental bulbous dome. While the inner dome keeps the height of the interior space in proportion, the large outer dome helps the structure stand out visually. An elevation drawing illustrating this structural system can be found in Figure $2 b$ [6]. 


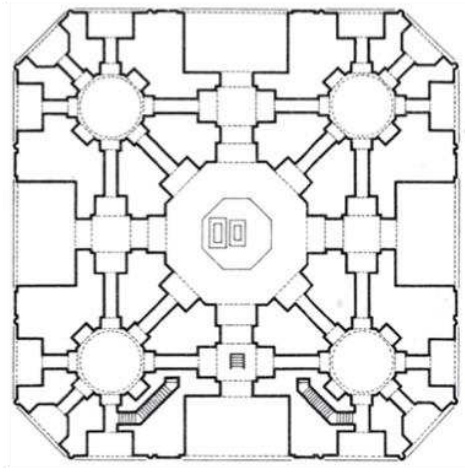

(a)

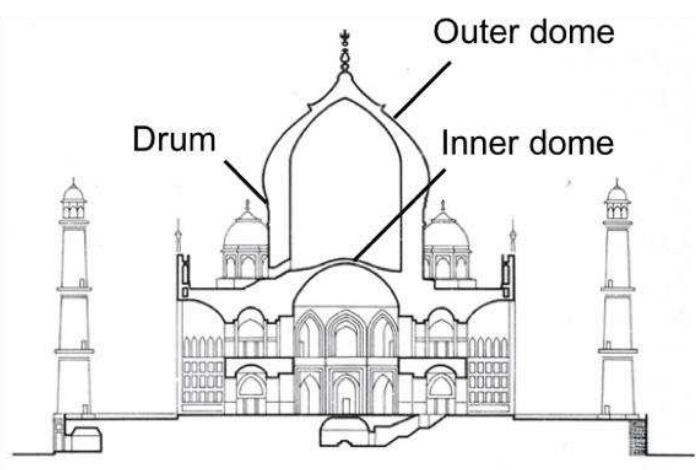

(b)

Figure 2: Taj Mahal (a) floor plan and (b) section (source ref. [2])

\subsection{Materials used for construction}

The materials used for construction of the Taj Mahal were sourced from all over India and Asia, and have been systematically investigated in detail and documented in $[3,5,6]$. The walls in the complex, many of which are several feet thick, were constructed of bricks with rubble inner cores and façades of either marble or sandstone fastened with iron dowels and clamps. The bricks typically measured 17.8-19.0 x 10.9-12.7 x 1.9-3.0 cm and were combined with lime mortar, while the façade slabs had a thickness of about $15.24 \mathrm{~cm}$. The bricks wero fired in local kilns, and the sandstone was brought all the located $402 \mathrm{~km}$ away with a combination o applied in sequential step process.
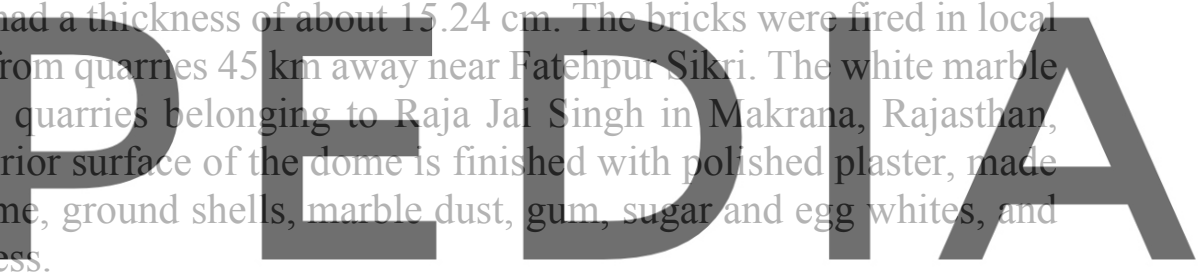

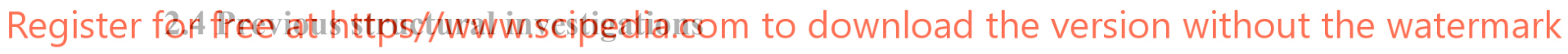

The first known structural investigation of the Taj Mahal, including a thorough examination of the sub-soil conditions and the foundation system, was carried out by Dayalan [5]. The dimensions of the structure were established using precise measurements and detailed drawings made available by the Archaeological Survey of India. Based on these dimensions, the weight of the dome was estimated to be $119,600 \mathrm{kN}$ and the weight of the supporting drum to be 59,800 $\mathrm{kN}$. Dayalan's structural analysis consisted of dividing the dome (up to a height of $22.9 \mathrm{~m}$ ) into 30 equal sections, constructing a diagram of forces acting at the center of gravity of each of the sections, based on which the stresses were determined. From this analysis, the maximum compressive stress at the base of the dome was determined to be $383.07 \mathrm{kPa}$, while a maximum compressive stress of $574.54 \mathrm{kPa}$ was recorded at the base of the supporting drum. According to [5] the walls of the cenotaph chamber that carry the weight of the drum and dome are very heavily loaded resulting in a stress level in the cenotaph walls of $766.01 \mathrm{kPa}$ which is almost twice the safe stress limit level for present day bricks with lime mortar. In fact, the signs of crushing detected in the cenotaph chamber are most likely due to the squeezing of mortar (which had likely deteriorated over time) under the action of these superimposed loads.

A more detailed structural analysis of the dome of the Taj under gravity loading was 
conducted using finite element modelling in Abaqus FEA [6]. From this analysis it was found that the maximum stresses experienced by the dome in both the hoop and meridional directions were less than the strengths of the brick and mortar, with the over-dimensioning of the structure effectively resulting in a safety factor of 5 for the dome [6]. This compares reasonably well with analyses conducted on the complete Taj Mahal structure using 3D finite element modelling in SESAM, which yielded a safety factor between 4 and 8 for the monument under vertical loading [9].

Studies concerning the seismic analysis and safety of the Taj Mahal have also been conducted at the University of Roorkee, however these make use of relatively simplified models such as the lumped mass and spring model [8].

\section{TAJ MAHAL DOME - DIMENSIONS AND GEOMETRY}

In order to determine the dimensions of the dome of the Taj Mahal needed to build the computational model for structural analysis, Mehrotra and Glisic [6] established one known reference dimension namely the external dimension of the drum as documented by Dayalan [5]. Using this as a reference dimension, all other defining dimensions were determined relative to this reference dimension. Figure 3 a presents the major dimensions of the dome as presented by Mehrotra and Glisic [6]. The dome has a constant thickness of 4 meters, from its base to a height of 15.5 meters above it. Dome thickness varies in the conical portion of the structure (i.e. the top 8 meters of the dome), starting with a thickness of 4.3 meters at the lower end, which

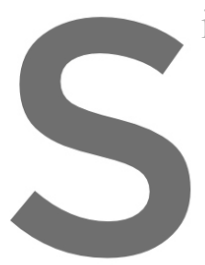
increases to 4.8 meters
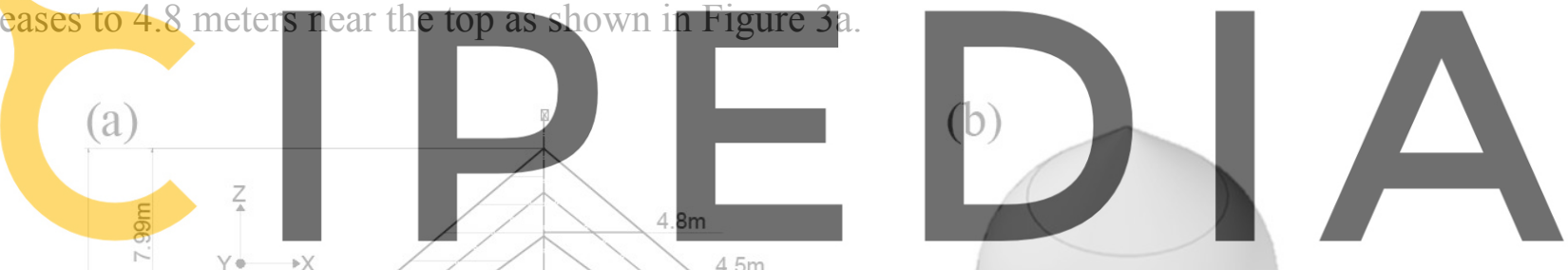

Register for free at hittpstg/www scjpedia.com to downlonl the version without the watermark
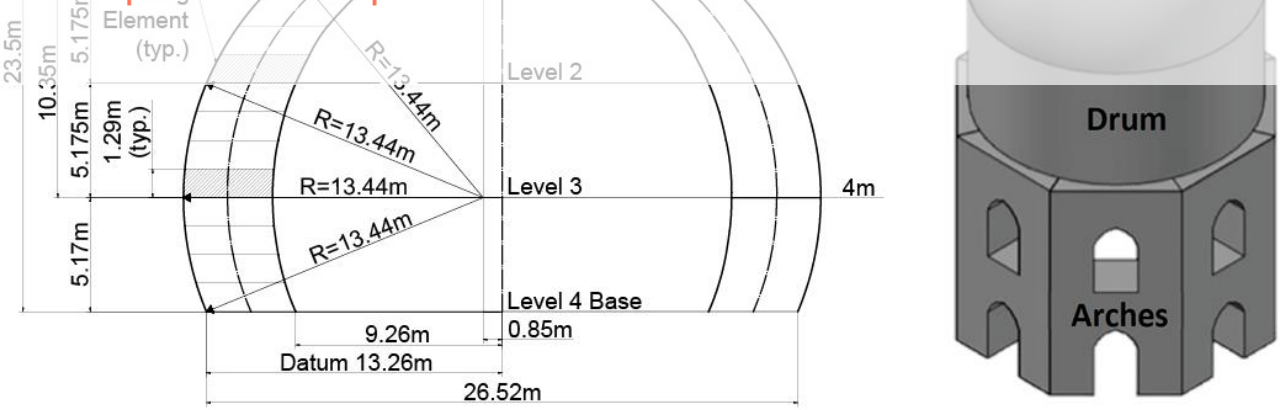

Figure 3: (a) Dome section showing ring dimensions and geometry and (b) Structural System - Taj Mahal

\section{STRUCTURAL SYSTEM}

The Moghul designers and engineers had developed an innovative structural system for the Taj Mahal consisting of the outer dome supported on a drum, seated on eight massive columns with arches spanning between these columns, as illustrated by Figure $3 \mathrm{~b}$ (reproduced from [6]). As reported in [5], it is likely that the Taj's outer dome with its bulbous geometrical form must experience a certain amount of tension in the lower part of its structure. In the absence of 
reinforcing techniques like outer metal bands during that period, the architects and master builders of the Moghul era managed to creatively achieve stability of the dome by using good quality bricks and mortar, and by gradually increasing the dome thickness [5].

As reported by Dayalan [5] and Viladkar et. al [9], this entire structure rests on a raft/mat $33.5 \mathrm{~m}$ thick, which rests on a thick sandy layer $9.1 \mathrm{~m}$ in depth, overlaying a $63.6 \mathrm{~m}$ thick clayey strata, founded on rock.

\section{STRUCTURAL ANALYSIS}

Dayalan's simplified structural analysis of the Taj Mahal [5] as well as the more detailed structural analysis as carried out by Mehrotra and Glisic [6] only considered gravity loads in the analyses. In this paper, a detailed structural analysis of the Taj Mahal dome has been carried out under the action of both gravity and seismic loads. Ideally it would be desirable to carry out a comprehensive structural analysis of the entire structure, incorporating the entire structural system e.g. the outer dome, inner shallow dome, the drum, and the arched cenotaph and its raft foundation. However, this proved to be infeasible due to modelling complexities and computational constraints, resulting in only the main dome of the structure being considered in this phase of the study.

\subsection{Finite Element Analysis - Part I}

The objective of the first part of the detailed structural analysis was to investigate the transfer

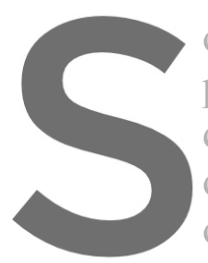

of forces/reactions

presented in Figure $3 a$

developed using shell,

over its height, which in tur

of 272 shell elements in the model (17 vertical $x$
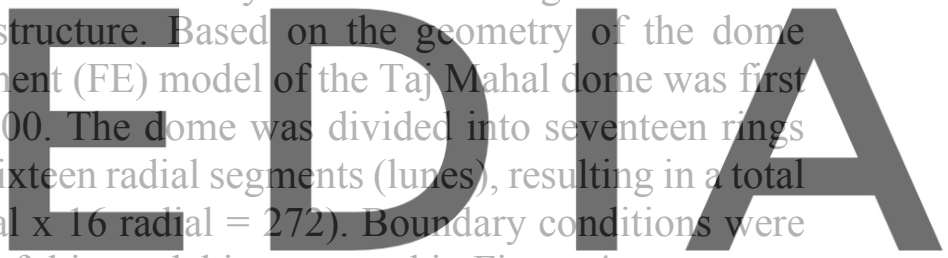

assumed to be pinned at the base. A 3D view of this model is presented in Figure 4.

Register for free at https//www.scipedia.com to download the version without the watermark

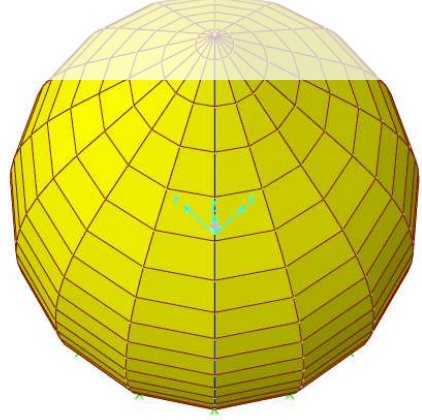

Figure 4: 3D FEA model of the Taj Mahal dome

The material properties adopted for this model are listed in Table 1. Note that the analyses conducted here assume an isotropic material model, which is not the case in reality. However the limited information regarding exactly how the bricks are arranged within the dome (i.e. concentrically/radially/combination of the two), made it challenging to define anisotropic material properties for the model. Thus these effects were neglected in the adopted modelling approach. 
Table 1: Material properties assumed for the FE model

\begin{tabular}{cc}
\hline Parameter & Value \\
\hline Density & $20.59 \mathrm{kN} / \mathrm{m}^{3}$ \\
\hline Modulus of elasticity & $3447.4 \mathrm{MPa}$ \\
\hline Poisson's ratio & 0.2 \\
\hline Unit compressive strength [11] & $2430 \mathrm{kPa}$ \\
\hline Unit tensile strength [11] & $300 \mathrm{kPa}$ \\
\hline Bond tensile strength [12] & $170 \mathrm{kPa}$ \\
\hline
\end{tabular}

The following three load cases are considered for analysis:

1. Dead load (self-weight only) $=101,705.83 \mathrm{kN}$

2. Seismic load $=0.25 \mathrm{~g}$, as obtained from the results of a study conducted by the Indian National Disaster Management Authority [10]

3. Combined load $=$ Dead + Seismic

and the forces/reactions are studied at four different levels of interest as listed in Table 2 and indicated in Figure 3a.

Table 2: Dome dimensions at the specified levels of interest
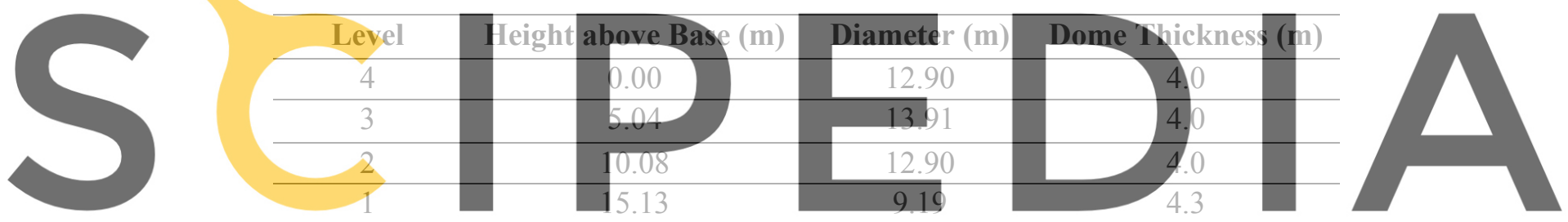

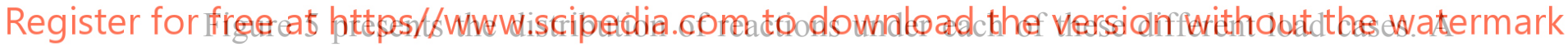
comparison of the distribution of reactions under the dead load only in the XY plane (Figures $5 b$ and c) illustrates that the forces appear to be pushing outward at the bulging part of the dome (Level 3, Figure 5c) and inward at the base (Level 4, Figure 5b).

A study of dome reactions under seismic loading at the base indicate that the reactions in the direction of the earthquake are maximum at the edges of the dome, and are minimum at the center of the dome in the line of the earthquake. Reactions in a direction normal to the earthquake show bulging in the left half of the dome; and contraction in the right half (Figure 5e). A study of the dome reactions under seismic loading at the bulge (Level 3) indicate that the reactions in the direction of the earthquake are more uniform on both the right and left side of the dome; and that the reactions in the direction normal to the earthquake show lesser bulging and contracting at this level (Figure 5d).

\subsection{Finite Element Analysis - Part II}

A more refined FEA model was also developed in SAP 2000 using eight node solid elements for investigating the stresses at different levels, and across the thickness of the dome. 

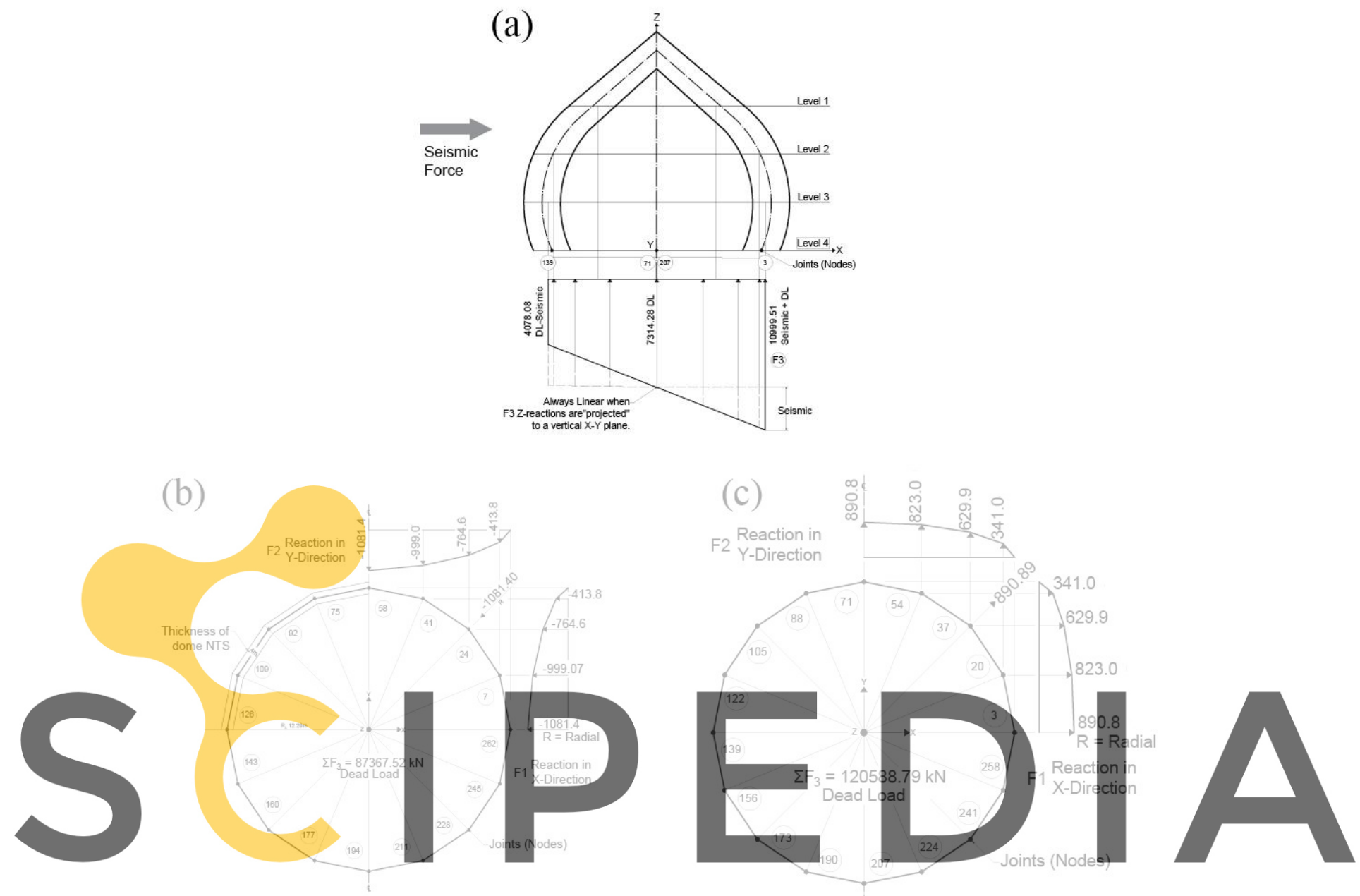

Register for free at https//www.scipedia.com to download the version without the watermark
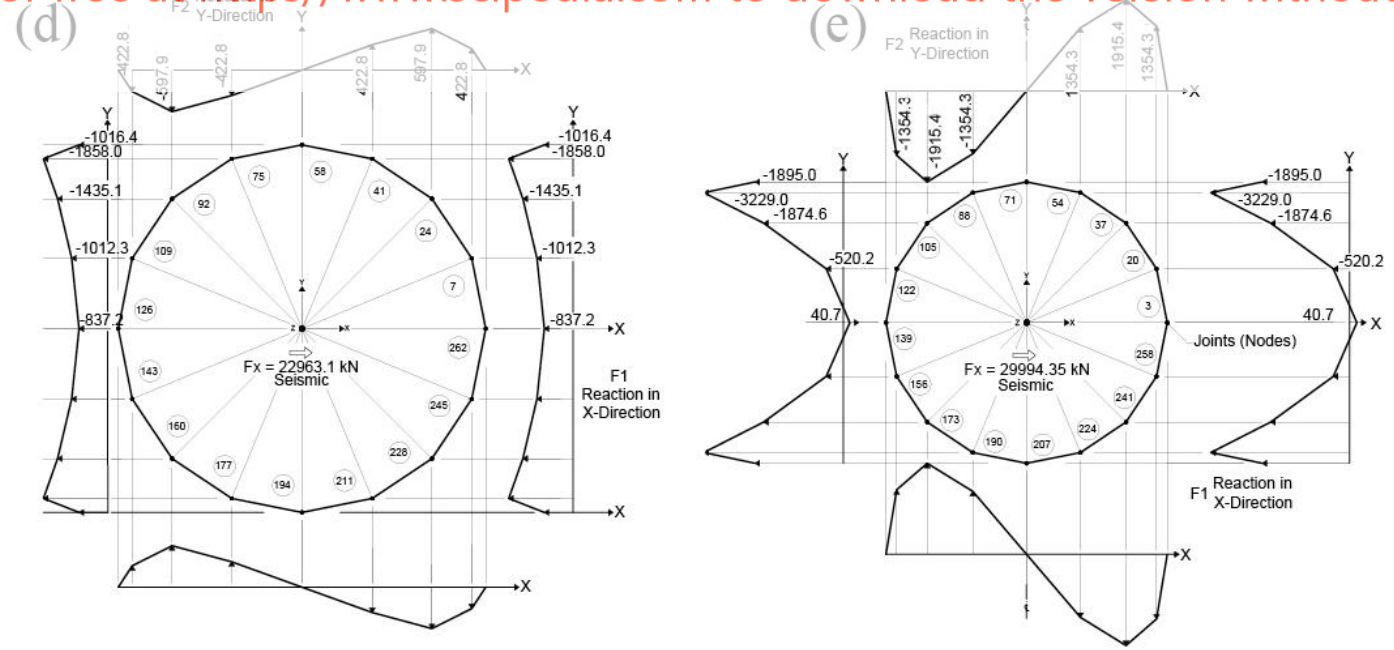

Figure 5: (a) distribution of vertical reactions - dead + seismic; (b) Level 3 (bulge) - XY reactions - dead load $\mathrm{kN}$; (c) Level 4 (base) - XY reactions - dead load - kN; (d) Level 3 (bulge) - XY reactions - seismic load - kN (e) Level 4 (base) - XY reactions - seismic load - $\mathrm{kN}$ 
As in the case of the FE shell model, the boundary conditions were modelled as pinned $(\mathrm{UX}=\mathrm{UY}=\mathrm{UZ}=0$ ), while the dome was divided into a series of rings over its height, which are then divided into one hundred and twenty radial segments (lunes). The dome was further discretized using solid elements, by dividing the dome thickness into four segments throughout the dome geometry up to $19.5 \mathrm{~m}$ above the base of the dome. Above the $19.5 \mathrm{~m}$ level, $4 \mathrm{~m}$ high solid cone shape elements were generated. The resulting FE model comprises 17644 solid elements, with 23050 joints (Table 3). Note that the material properties and load cases adopted for this model are the same as for the simplified model with the shell elements.

Table 3: Dome dimensions as they relate to SAP 2000 software

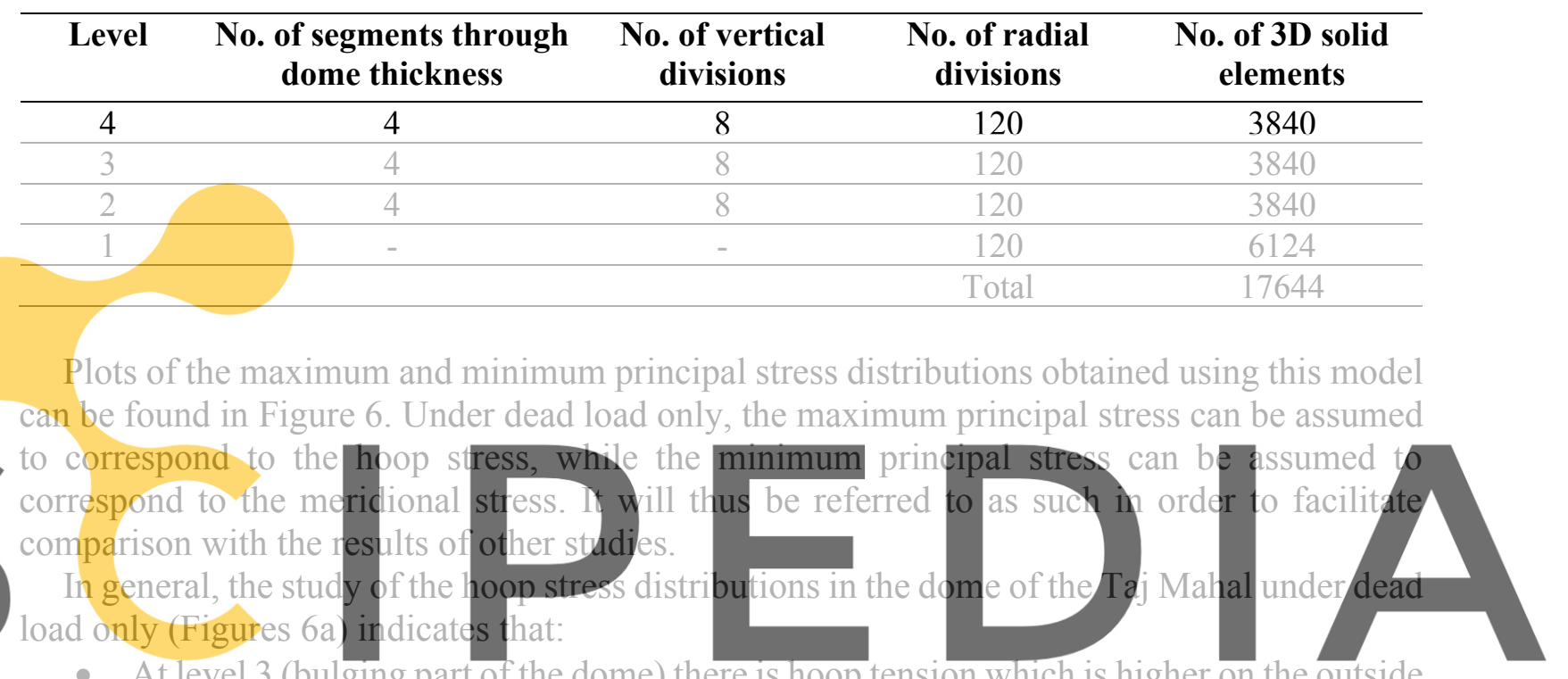

- At level 3 (bulging part of the dome) there is hoop tension which is higher on the outside

Register for free at https/ www.scipedia.com to download the version without the watermark the dome and lower compression on the inside surface of the dome indicating that there

is rotation and bulging out even at the base of the dome

A comparison of the maximum hoop and meridional stresses obtained from this structural analysis, with those obtained by Dayalan [5] and Mehrotra \& Glisic [6] are presented in Table 4. As Table 4 indicates, under the influence of the dead load only, maximum hoop tensile stress occurs at the outer surface of Level 3 (bulge), with a value of $70.8 \mathrm{kPa}$. This lies between the maximum hoop tensile stress values reported by Dayalan [5] and Mehrotra \& Glisic [6], and is found to be within the safe limits of the $300 \mathrm{kPa}$ tensile strength of brick [11] as well as the 170 $\mathrm{kPa}$ tensile bond strength of the brick-mortar interface (perpendicular to the joints, as this is the limiting case) [12]. At the base (Level 4) the hoop stress reverses to compression and varies from $-202.0 \mathrm{kPa}$ at the outer dome surface to $-39.3 \mathrm{kPa}$ at the inner dome surface, with an average value of $-120.6 \mathrm{kPa}$ which is larger than the maximum hoop stresses values reported by Dayalan [5] and Mehrotra \& Glisic [6], but still within the safe limits of brick's compressive strength of $2430 \mathrm{kPa}$ [11].

Similarly, a comparison of the meridional stresses under the dead load (Figure 6c) indicates that as in $[5,6]$ the maximum meridional stress is recorded at the outer surface of Level 4 (base) 
with a maximum value of $-833.4 \mathrm{kPa}$ (compression), which reduces to $-168.6 \mathrm{kPa}$ at the inner surface of the dome, resulting in average value of $-501.0 \mathrm{kPa}$ which is within the range of the values reported by Dayalan [5] and Mehrotra \& Glisic [6] and well within the safe limit of brick's compressive strength.

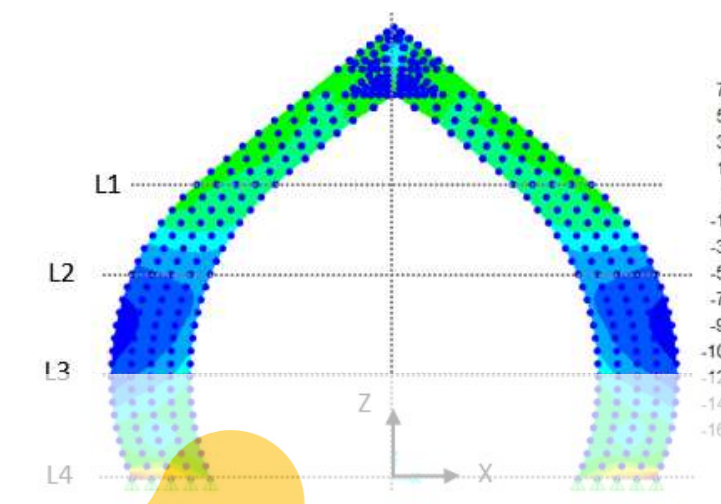

(a)
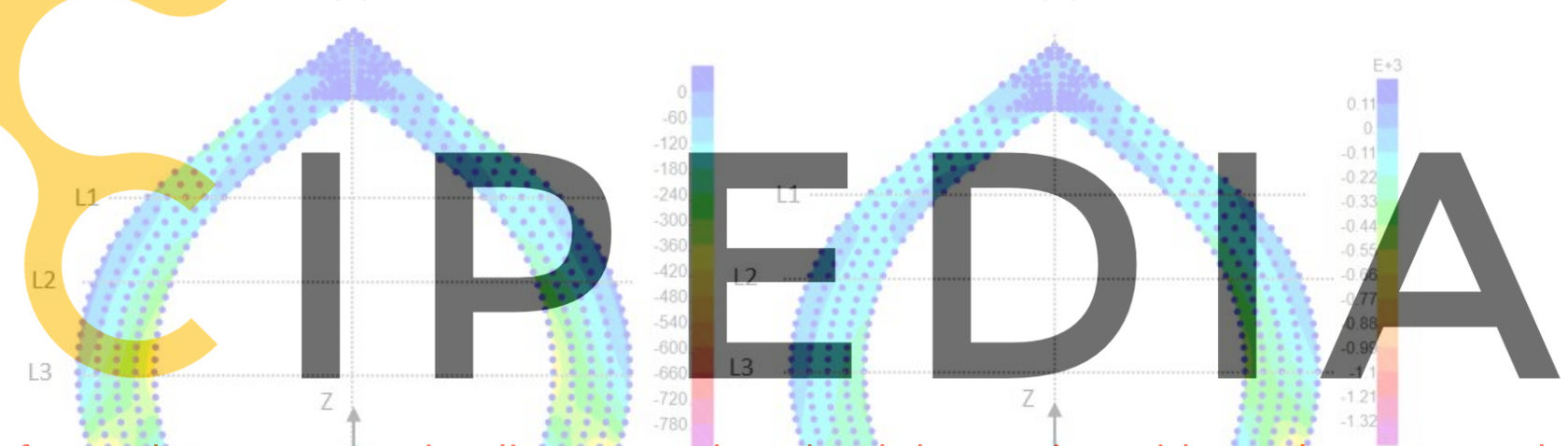

Register for free at https//www.scipedia.com to download the version without the watermark

Figure 6: (a) Maximum principal stress - dead load (kPa) (b) maximum principal stress - combined dead + seismic load $(\mathrm{kPa})(\mathrm{c})$ minimum principal stress - dead load $(\mathrm{kPa})(\mathrm{d})$ minimum principal stress - combined dead + seismic load $(\mathrm{kPa})$

Table 4: Comparison of maximum hoop and meridional stresses obtained under dead load only with those obtained by Dayalan [5] and Mehrotra \& Glisic [6]

\begin{tabular}{ccccccccc}
\hline Level & \multicolumn{3}{c}{ Max Hoop Stress (kPa) } & \multicolumn{3}{c}{ Max Meridional Stress (kPa) } \\
\hline & Dayalan & $\begin{array}{c}\text { Mehrotra } \\
\text { \& Glisic }\end{array}$ & Outer & Inner & Dayalan & $\begin{array}{c}\text { Mehrotra } \\
\text { \& Glisic }\end{array}$ & Outer & Inner \\
\hline $\mathbf{4}$ & -65.0 & -110.0 & -202.0 & -39.3 & -565.0 & -478.7 & -833.4 & -168.6 \\
\hline $\mathbf{3}$ & 266.0 & 40.0 & 70.8 & 44.8 & -339.0 & -75.0 & -152.7 & -410.3 \\
\hline $\mathbf{2}$ & -123.0 & -65.0 & 60.4 & 51.9 & -158.0 & -107.6 & -94.5 & -244.0 \\
\hline $\mathbf{1}$ & & & -66.9 & -55.5 & & & -151.1 & -105.5 \\
\hline
\end{tabular}


Under the influence of the combined dead and seismic loads, the maximum principal stresses are generally found to be higher on the east side of the dome, and lower on the west side, with the outer surface once again recording larger stresses than the inner surface (Figure 6b). The maximum principal tensile stress is found to migrate from Level 3 (bulge) to Level 2, with a maximum value of $139.8 \mathrm{kPa}$ recorded on the outer surface of the east side of the dome (Table 5). Note that this tensile stress is once again within the limiting tension capacity of both the brick material and the brick-mortar interface.

Similarly, the minimum principal stresses under combined loading (Figure 6d) are generally found to be higher on the east side of the dome and lower on the west side. However, in this case the inner surface tends to record larger stresses than the outer surface (Table 6), with the exception of the base (Level 4) where a compressive stress of $-1402 \mathrm{kPa}$ is recorded on the outer surface of the dome. Note that this compressive stress is once again within the $2430 \mathrm{kPa}$ compressive strength of brick. Furthermore, a tensile stress of $170.4 \mathrm{kPa}$ is also recorded on the inner surface of the dome. While this is still less than the tensile strength of the brick unit, it is equal to the $170 \mathrm{kPa}$ tensile strength of the brick-mortar interface, which could result in some cracking of the structure at its base.

Table 5: Maximum principal stress $(\mathrm{kPa})$ under combined dead and seismic load

\begin{tabular}{ccccc}
\hline Level & \multicolumn{2}{c}{ West Side } & \multicolumn{2}{c}{ East Side } \\
\hline & Outer & Inner & Outer & Inner \\
\hline 4 & -65.3 & -61.2 & -338.9 & 28.2 \\
\hline 3 & 43.0 & 26.2 & 101.7 & 67.0 \\
\hline 2 & -31.0 & -17.1 & 139.8 & 108.1 \\
\hline 1 & -133.3 & -102.8 & 35.8 & 22.1 \\
\hline
\end{tabular}

Table 6: Minimum principal stress $(\mathrm{kPa})$ under combined dead and seismic load

\begin{tabular}{ccccc}
\hline Level & \multicolumn{2}{c}{ West Side } & \multicolumn{2}{c}{ East Side } \\
\hline & Outer & Inner & Outer & Inner \\
\hline 4 & -266.1 & -268.9 & -1402.0 & 170.4 \\
\hline 3 & -106.7 & -321.0 & -199.6 & -500.6 \\
\hline 2 & -94.5 & -149.4 & -95.2 & -338.8 \\
\hline 1 & -162.5 & -75.6 & -151.9 & -136.2 \\
\hline
\end{tabular}

\section{CONCLUSIONS}

In this paper the results of a seismic analysis of the dome of the Taj Mahal are presented. Results include the mechanism of load transfer, and stress distributions in the dome under gravity and seismic loads. Under the influence of gravity alone (dead load), both the maximum hoop and meridional stresses recorded in the dome are found to be well within the tensile and compressive strengths of brick (safety factors of 4.2 and 2.9 respectively) as well as the tensile bond strength of the masonry (safety factor of 2.4), and compare reasonably well with the results of similar analyses conducted in the literature.

Similarly, under the influence of the combined gravity and seismic loads, the maximum principal tensile stress $(139.8 \mathrm{kPa}$ at level 2 at outer surface on the east side) was again found 
to be within the limiting tensile capacity of both the brick material and brick-mortar interface, but with the safety factors now reducing to 2.1 and 1.2 respectively. Additionally, the maximum principal tensile stress was found to migrate from level 3 (bulge) to level 2 due to the dome geometry.

Furthermore, under the combined load case, the minimum (maximum magnitude) principal compressive stress (-1402 $\mathrm{kPa}$ at level 4 at outer surface on east side) was also found to be less than the compressive strength of the material, but with the safety factor now reducing to 1.7. Additionally, a tensile stress of $170.4 \mathrm{kPa}$ was also recorded on the inner surface of the dome. While this is still less than the limiting tensile capacity of the brick unit, it is however equal to the strength of the brick-mortar interface, which could result in some cracking of the structure at its base. It is proposed to further investigate this potential cracking behavior in the next phase, while also examining the effect of the supporting substructure on the dynamic (seismic) response of the dome.

\section{ACKNOWLEDGEMENTS}

The authors acknowledge the valuable assistance of Dr. Ali Roufegarinejad and Mr. Mason Walters S.E. of Forell, Elsesser structural engineers, San Francisco, California during the preparation of this paper. The authors acknowledge the assistance of Alex Limber, fourth year student in the college of architecture and environmental design at Cal Poly State University, San Luis Obispo, California.

\section{REFERENCES}

[1] Gascoigne, B. The Great Moghuls, Harper and Row, Publishers, New York (1971)

[2] Volwahsen, A. Living Architecture: Islamic Indian, Grosset \& Dunlap, Publishers, New York, (1970)

[3] Koch, E. Moghul Architecture, Oxford University Press, New Delhi, India (2002)

[4] Bunce, F. Islamic Tombs in India, D. K. Printworld (P) Ltd., New Delhi, India (2004)

[5] Dayalan, D. Taj Mahal and Its Conservation, Abhishek Prakashan, Delhi, India (2009)

[6] Mehrotra, A. and Glisic, B. Deconstructing the Dome: A Structural Analysis of the Taj Mahal, J. Int. Ass. Shell Spat. Struct. (2015), 56(4): 269-284.

[7] Computers and Structures, Inc. SAP 2000 Software, Walnut Creek, California (2019)

[8] Dubey, R.N., Thakkar, S.K. and Gupta, A. Seismic Analysis for Safety Evaluation of Taj Mahal Monument. In: Proceedings of the $11^{\text {th }}$ World Conference on Earthquake Engineering, (1996).

[9] Viladkar, M.N., Bhandari, N.M., Godbole, P.N. and Trikha, D.N. Three-Dimensional Finite Element Analysis of Taj Mahal Structure. In: Proceedings of the $5^{\text {th }}$ International Conference on the Structural Analysis of Historical Constructions (SAHC2006), (2006).

[10] National Disaster Management Authority (NDMA). Development of Probabilistic Seismic Hazard Map of India, Government of India, New Delhi (2011).

[11] Agarwal, P. and Thakkar, S.K. A comparative study of brick masonry house model under quasi-static and dynamic loading, ISET Journal of Earthquake Technology (2001), 38: 103-122.

[12] Singhal, V. and Rai, D.C. Suitability of Half-Scale Burnt Clay Bricks for Shake Table Tests on Masonry Walls, Journal of Materials in Civil Engineering (2014), 26: 644-657. 